\title{
Co-expression of $\mathrm{P} \mathrm{A}_{35-43} / \mathrm{B2} \mathrm{m}$ fusion protein and co-stimulatory molecule CD80 elicits effective anti-tumor immunity in the P815 mouse mastocytoma tumor model
}

\author{
XINGQIAN ZHANG ${ }^{*}$, WENHAN MEI* , LEILEI ZHANG, HAI YU, XIAOPING ZHAO, \\ XIANQUN FAN, GUANXIANG QIAN and SHENGFANG GE
}

\begin{abstract}
Department of Biochemistry and Molecular Biology, Research Center for Human Gene Therapy, School of Medicine, Shanghai Jiao Tong University, No. 280 Chongqing Road South, Shanghai 200025, P.R. China
\end{abstract}

Received March 20, 2009; Accepted May 19, 2009

DOI: 10.3892/or_00000557

\begin{abstract}
A strong CTL response is dependent upon a high level of expression of specific class I major histocompatibility complex (MHC)/peptide complexes at the cell surface. An epitope-linked $\beta 2$-microglobulin ( $(32 \mathrm{~m})$ molecule could provide a simple and more efficient means to enhance the formation of defined MHC/peptide complexes. However, the ability of an epitope-linked $32 \mathrm{~m}$ molecule to elicit primary CTL responses in vivo is still unknown. In this study, we modified the P1A tumor cell vaccine by addition of the tumorassociated epitope (TAE)-linked $32 \mathrm{~m}$ molecule and costimulatory molecule CD80 to improve the efficiency in the application of the vaccine. A eukaryotic co-expression vector consisting of the $\mathrm{P}_{1} \mathrm{~A}_{35-43}$-linked $\mathrm{B2} \mathrm{m}$ molecule and the murine $C D 80$ gene was constructed. P815 cell lines stably expressing $\mathrm{P}_{1 \mathrm{~A}_{35-43}}$-linked $\mathrm{B} 2 \mathrm{~m}$ molecule and/or CD80 were established after transfection, by selection under G418. Administration of these inactivated tumor cell vaccines allowed the $\mathrm{TAE}$-specific $\mathrm{CD} 8{ }^{+} \mathrm{T}$ cell responses to be examined in vivo. Our results indicate that immunization with P815 cells expressing both the $\mathrm{P}_{1 \mathrm{~A}_{35-43}}$-linked $\mathrm{B2} \mathrm{m}$ molecule and the murine $C D 80$ gene elicited a significantly stronger antitumor immune response than the singlemodified tumor cell vaccines (expressing either $\mathrm{P}_{1} \mathrm{~A}_{35-43^{-}}$ linked $32 \mathrm{~m}$ or CD80 alone). These findings support the feasibility and effectiveness of developing a dual-modified tumor cell vaccine consisting of the epitope-linked $32 \mathrm{~m}$ molecule and a co-stimulatory molecule.
\end{abstract}

Correspondence to: Dr Shengfang Ge, Department of Biochemistry and Molecular Biology, Research Center for Human Gene Therapy, School of Medicine, Shanghai Jiao Tong University, No. 280 Chongqing Road South, Shanghai 200025, P.R. China

E-mail: geshengfang@sjtu.edu.cn

${ }^{*}$ Contributed equally

Key words: tumor vaccine, epitope, $\beta 2$ microglobulin, murine CD80

\section{Introduction}

Major histocompatibility complex (MHC) class I molecules are heterotrimers consisting of a transmembrane (type I) heavy chain, a soluble light chain [ $\beta 2$-microglobulin (B2m)], and a peptide ligand of typically 8-10 amino acids. Complete assembly of the heterotrimer is necessary for ER egress and stable surface expression of class I molecules $(1,2)$. Since the density of specific MHC/peptide complexes on the cell surface can influence $\mathrm{T}$ cell responsiveness (3-5), the ability to express high levels of a particular class I complex could be potentially useful for eliciting strong CTL responses in the development of vaccinations or immunotherapy.

One potential approach to augmenting the surface display and immunogenicity of an epitope is to physically couple it to its presenting MHC molecule. The resulting fusion proteins have been shown to elicit CTL responses when expressed in transfected cells (6-8). More recently, it has been shown that generating an epitope-linked $\beta 2 \mathrm{~m}$ molecule could provide a simple and more efficient means of enhancing the formation of defined MHC/peptide complexes (9-11). Previously, we have reported that the expression of the $\mathrm{OVA}_{257-264}$-linked $32 \mathrm{~m}$ fusion molecule increases the formation of $\mathrm{H} 2-\mathrm{K}^{\mathrm{b}}-\mathrm{OVA}$ molecules on the cell surface of EL-4 cells (12). However, the ability of peptide- $\beta 2 \mathrm{~m}$ molecules to elicit primary CTL responses in vivo is still unknown. In the present study, we examined the antitumor effects of genetically engineered P815 cells expressing the epitope-linked $\beta 2 \mathrm{~m}$ molecule in the mouse mastocytoma tumor model. Induction of a T-cell response to an antigen usually requires two signals $(13,14)$. Signal 1 is delivered to the TCR via the peptide-MHC complex of the APC. Signal 2 involves the interaction of a costimulatory molecule of the APC with its ligand on the APC. Data are emerging that the level of signal 1 required for effective T-cell activation is influenced by the level of expression of signal 2 (15). CD80 plays an important role in the activation of $\mathrm{T}$ cells, exogenous costimulatory molecules in tumor cells can lead to the strengthening of the effects of $\mathrm{T}$ cells, including cell proliferation, secretion of cytokine and CTL activity $(16,17)$. We have successfully constructed a coexpression vector of CD80 and GFP-tagged $\mathrm{K}^{\mathrm{b}}$ molecules to enhance the response of specific $\mathrm{T}$ cells and thus increase the 
uptake of the antigen peptide-MHC class I-GFP complex (18). Therefore, we also examined the role of CD80, a member of the B7 family, in the T-cell response induced by genetically engineered P815 cells.

\section{Materials and methods}

Animals and cells. Female DBA/2 mice (H-2 $)$, 6- to 8-weeksold, were purchased from the Experimental Animal Center of Shanghai (China) and bred in our specific pathogen-free animal facility. P815, a mastocytoma cell line of DBA/2 origin, was cultured in RPMI-1640 media supplemented with $10 \%$ heat-inactivated fetal calf serum, $2 \mathrm{mM}$ L-glutamine, $1 \mathrm{mM}$ sodium pyruvate, $0.1 \mathrm{mM}$ HEPES, $5 \mu \mathrm{M}$ 2-ME, $100 \mathrm{IU} / \mathrm{ml}$ penicillin and $100 \mu \mathrm{g} / \mathrm{ml}$ streptomycin [all from Gibco (Carlsbad, CA, USA)] at $37^{\circ} \mathrm{C}$ in a humidified atmosphere consisting of $5 \% \mathrm{CO}_{2}$.

Construction of eukaryotic expression vectors. The plasmids, pcDNA3/P1A and pcDNA3/P198, are the eukaryotic expression vectors pcDNA3 (Invitrogen, CA, USA) containing the human $32 \mathrm{~m}$ leader followed by either the $\mathrm{P} \mathrm{A}_{35-43}$ or $\mathrm{P} 198_{14-22}$ peptide epitope tethered to the $32 \mathrm{~m}$ through an 8 -amino acid (8aa) linker $\left[(\mathrm{GGGS})_{2}\right]$. The constructs were generated using a template from a similar construct, the human $\beta 2 \mathrm{~m}$ leader$\mathrm{OVA}_{258-265}-8$ aa linker-hß2m, inserted as a HindIII/XbaI fragment in pcDNA3 (12). The $\mathrm{OVA}_{258-265}$ peptide sequence was replaced with either the $\mathrm{P}_{1 \mathrm{~A}_{35-43}}$ or $\mathrm{P} 198_{14-22}$ sequence using PCR. Using the BamHI site in the linker sequence, a PCR product covering the leader sequence, the peptide and the first 12 bases of the linker was generated using the following reverse primers: 5'CGGGATCCTCCTCCGAAGA CCAGCCACCCTAGATAAGGCAGAGCCTCCAGGCCA GAAAG3' for pcDNA3/P1A; and 5'CGGGATCCTCCTCCC AGAGTGGTTGTCACTGCCTGGTACTTAGCCTCCAGG CCAGAAAG3' for pcDNA3/P198. The forward primer, 5'CCCAAGCTTATGTCTCGCTCCGTG3' (containing a HindIII site) was used for both constructs. PCR products were subsequently cloned, as a HindIII/BamHI fragment, into the template vector.

Full-length mouse CD80 cDNA was amplified by RT-PCR from Con A-activated C57BL/6 splenocytes. The former primer is 5'TCCCAAGCTTCAAAGCATCTGAAACCA TGGCT3' (containing a HindIII site), the reverse primer is 5'TGCTCTAGACTAAAGGAAGACGGTC3' (containing an $X b a \mathrm{I}$ site). Then CD80 cDNA was cloned into the pcDNA3 and pGL3/promoter plasmids (Promega, Madison, WI, USA). The resulting plasmids were named pcDNA3/CD80 and pGL3/CD80, respectively. To construct the co-expression vector consisting of the peptide-linked $\beta 2 \mathrm{~m}$ molecule and CD80, a BglII/SmaI fragment (covering the CMV promoter, the leader, the peptide, the linker, $\mathrm{h} \beta 2 \mathrm{~m}$ and the SV40 polyA signal) of pcDNA3/P1A or pcDNA3/P198 was digested and cloned into pGL3/CD80, and were named pGL3/CD80-P1A or pGL3/CD80-P198, respectively. All of these constructs were confirmed by sequence analysis.

Stable transfection of P815 cells. P815 cells were transfected with pGL3/CD80-P1A, pGL3/CD80-P198, pcDNA3/P1A, pcDNA3/P198, pcDNA3/CD80 and pcDNA3 by electro- poration using a Bio-Rad gene pulser II (Hercules, CA, USA). The electroporation was performed on cells diluted in serum-free RPMI-1640 media. Cells were pulsed at $960 \mu \mathrm{F}$ and $0.25 \mathrm{kV} / \mathrm{cm}$. The co-transfection of $\mathrm{pSV} 40 /$ neo (which carries a eukaryotic resistance marker) and pGL3/CD80-P1A or pGL3/CD80-P198 (1:50) was selected using G418. Fortyeight hours after transfection, the transfected cells (designated as P815/CD80-P1A, P815/CD80-P198, P815/P1A, P815/ $\mathrm{P} 198, \mathrm{P} 815 / \mathrm{CD} 80$ and $\mathrm{P} 815 /$ neo, respectively) were selected in complete media containing $500 \mu \mathrm{g} / \mathrm{ml} \mathrm{G} 418$ (Invitrogen) and were subsequently cloned by limiting dilution. The expression of the peptide-linked $32 \mathrm{~m}$ fusion molecule was confirmed by PCR and RT-PCR. Mouse CD80+ P815 cells were identified by FACS analysis, using an anti-CD80 antibody (eBioscience, San Diego, CA, USA). A representative clone of each transfectant was selected for further studies.

Tumorigenicity of gene-modified tumor cells. The genemodified P815 cells were tested for tumorigenicity by subcutaneous (s.c.) transplantation of syngeneic DBA/2 (H-2 $\left.{ }^{\mathrm{d}}\right)$ mice. DBA/2 mice (six mice per group) were injected s.c. in the right flank with $1 \times 10^{5} \mathrm{P} 815$ cells stably transfected with the backbone vector, peptide-linked $\beta 2 \mathrm{~m}$ molecule and/or CD80 vector pcDNA3, pGL3/CD80-P1A, pGL3/CD80P198, pcDNA3/P1A, pcDNA3/P198 or pcDNA3/CD80. The tumor size was measured by vernier calipers every 4 days. Animal experiments were performed in accordance with institutional guidelines for animal care by Jiao Tong University (19).

Immunization with gene-modified tumor cells. DBA/2 (H-2 $\left.{ }^{\mathrm{d}}\right)$ mice (three mice per group) were injected s.c. in the right flank with $1 \times 10^{6}$ P815/P1A-CD80, P815/P1A, P815/CD80 or $\mathrm{P} 815 / \mathrm{Neo}$ cells (irradiated with $\mathrm{Cs}^{137}$ ). The injections were repeated one week later and the mice were sacrificed 14 days after the second immunization for the collection of lymphocytes. Spleen mononuclear cells (SMC) were isolated by density gradient centrifugation (NycoPrep, Axis-Shield PoC AS, Norway) and used in H-2L/LPYLGWLVF pentamer staining and IFN- $\gamma$ ELISPOT assays.

Ex vivo enumeration of tumor associated epitope (TAE)specific $C D 8^{+} T$ cells with MHC pentamers. Pentamer staining assays were performed with an R-PE labeled Pro5 MHC Pentamer H-2Ld/LPYLGWLVF kit (Proimmune, Oxford, UK) according to the manufacturer's instructions. Briefly, $5 \times 10^{5}$ SMC were incubated with one test $(10 \mu 1) \mathrm{R}-\mathrm{PE}$ labeled H-2Ld/LPYLGWLVF Pentamer for $10 \mathrm{~min}$ at room temperature $\left(22^{\circ} \mathrm{C}\right)$. After washing, cells were incubated with one test anti-CD8 ${ }^{+}$FITC (clone KT15) for 20 min at $4^{\circ} \mathrm{C}$. Following a further two washes, cells were fixed in formaldehyde and analyzed using a FACSCalibur with CellQuest (BD Biosciences, San Jose, CA, USA).

ELISPOT assays. The number of IFN- $\gamma$-secreting, peptide specific $\mathrm{T}$ cells in the fresh splenocyte preparations was determined by the ELISPOT method. ELISPOT assays were performed with a Mouse IFN- $\gamma$ ELISPOT kit (U-CyTech Biosciences, Utrecht, The Netherlands) according to the manufacturer's instructions. Briefly, 96-well plates were 
coated with $50 \mu 1$ of diluted coating antibodies overnight at $4^{\circ} \mathrm{C}$. After washing five times with washing buffer [PBS containing $0.05 \%$ Tween-20 (PBST)], the plates were blocked with $200 \mu \mathrm{l}$ blocking solution B at $37^{\circ} \mathrm{C}$ for $1 \mathrm{~h}$. After removal of the blocking media, SMC were incubated at $2 \times 10^{5}$ per well in six separate wells in a total volume of $100 \mu 1 \mathrm{RPMI}-1640$ containing $10 \%$ FCS, in the presence or absence of $8 \mu \mathrm{g} / \mathrm{ml}$ P1A non-apeptide (LPYLGWLVF, Proimmune) for $24 \mathrm{~h}$. Plates were washed three times with PBST, followed by incubation with biotinylated detection antibodies (100 $\mu \mathrm{l} /$ well) at room temperature for $2 \mathrm{~h}$. Plates were washed three times with PBST and PBS alone, then $50 \mu \mathrm{l}$ of GABA solution was added and samples were incubated at room temperature for $2 \mathrm{~h}$. After washing five times with PBST, $30 \mu \mathrm{l}$ of freshly prepared Activator I/II solution was added. The plates were incubated at room temperature in the dark. The colorimetric reaction was stopped by washing the plates under running water. Plates were allowed to dry, and the number of spots was read on an ELISPOT reader (Bioreader ${ }^{\circledR} 4000$ PRO-X, Germany). Data are presented as the mean number of spot forming units per $2 \times 10^{5}$ cells \pm standard error of the mean (SEM).

Challenge experiments following immunization with genemodified tumor cells. DBA/2 mice were injected i.p. with either $1 \times 10^{6} \mathrm{P} 815 / \mathrm{CD} 80-\mathrm{P} 1 \mathrm{~A}$ cells (irradiated by $\mathrm{Cs}^{137}$ ), P815/CD80 cells (irradiated by $\mathrm{Cs}^{137}$ ) or PBS (20). Before injection, tumor cells were washed twice in PBS, re-suspended in $1 \mathrm{ml}$ PBS, then injected i.p. using a 21-gauge needle. Three weeks later, $4 \times 10^{5}$ wild-type P815 cells were injected i.p. and the incidence of death was monitored daily to determine the survival rate of the mice.

Statistical analysis. The data were expressed as mean \pm SEM. Statistical analyses were performed using an unpaired Student's t-test. A value of $\mathrm{P}<0.05$ was considered to be statistically significant.

\section{Results}

In vivo tumor growth of gene-modified P815 cells. The expression of fusion protein and CD80 in G418 selected P815 cells which had been transfected with different plasmids is shown in Fig. 1A. DBA/2 mice were injected with different G418 screened 1x105 P815 cells and tumor development was monitored. As shown in Fig. $1 \mathrm{~B}$, the in vivo growth of P815 cells co-expressing the peptide-linked $\beta 2 \mathrm{~m}$ molecule and CD80 (P815/CD80-P1A, P815/CD80-P198) was significantly slower than P815 cells transfected with other genes, including the peptide-linked $\beta 2 \mathrm{~m}$ molecule alone or CD80 alone gene modified P815 cells (P815/P1A, P815/ $\mathrm{P} 198$ and $\mathrm{P} 815 / \mathrm{CD} 80)(\mathrm{P}<0.01)$. In contrast, the growth of the P815/CD80-P1A transfected cells was slower than that of the P815/CD80-P198 transfected cells $(\mathrm{P}<0.05)$. The level of in vitro proliferation of the gene-modified P815 cells was assessed by tetrazolium bromide (MTT) colorimetry. No differences were observed between the gene-modified and wild-type P815 cells (data not shown), suggesting that decreased tumorigenicity was not due to impaired proliferation of the gene-modified cells.
In order to eliminate the influence of transfection efficiency on the tumorigenicity of gene-modified P815 cells, monoclonal transgene expressing P815 subline cells were selected from transfected cells by limiting dilution and G418 selection. The tumorigenicity of these sublines was assessed (Fig. 1C). DBA/2 mice (six mice per group) were injected s.c. with $1 \times 10^{5}$ wild-type P815 cells or stably transfected P815 sublines. Tumors were monitored every 2-4 days once the tumor became palpable. We found that tumors derived from the CD80-expressing P815 sublines grew significantly slower than those from the non-CD80-expressing P815 sublines and wild-type P815 cells $(\mathrm{P}<0.01)$. However, no significant difference between the P815 cells transfected with the peptidelinked $32 \mathrm{~m}$ molecule alone and the wild-type P815 cells was observed (Fig. 1C).

Analysis of antigen-specific $C D 8^{+} T$ cells from immunized mice. To investigate the potential mechanism underlying the differences in tumorigenicity of the gene-modified P815 cells, we immunized mice with P815/neo, P815/P1A, P815/ CD80 and P815/CD80-P1A and analyzed the frequency of P1A-specific T cells. Splenocytes from the immunized mice were isolated and stained with $\mathrm{H}-2 \mathrm{~L} / \mathrm{d} / \mathrm{LP} Y \mathrm{LGWLVF}$ pentamers to assess the frequency of antigen-specific CTL precursors (CTLp). The co-staining of the H-2L d/LPYLGWLVF pentamer with anti-CD8 ${ }^{+}$, indicates that immunization with P815/P1A, $\mathrm{P} 815 / \mathrm{CD} 80$ and $\mathrm{P} 815 / \mathrm{CD} 80-\mathrm{P} 1 \mathrm{~A}$ results in a significant induction of pentamer-positive $\mathrm{CD}^{+} \mathrm{T}$ cells (Fig. 2). We found that P815/CD80-P1A-immunized mice had the highest number of pentamer positive $\mathrm{CD}^{+} \mathrm{T}$ cells (Fig. 2D). Surprisingly, the overall frequency of LPYLGWLVF-specific $\mathrm{CD}^{+} \mathrm{T}$ cells after the P815/P1A and P815/CD80 immunizations were very similar (Fig. $2 \mathrm{~B}$ and $\mathrm{C}$ ). These results show that the expression of peptide-linked $B 2 \mathrm{~m}$ molecule in P815 cells elicits a TAE-specific $\mathrm{CD}^{+} \mathrm{T}$ cell response that is enhanced by the co-expression of CD80.

IFN- $\gamma$-producing cell frequency of splenic lymphocytes from immunized mice. To determine whether the co-expression of the peptide-linked $\beta 2 \mathrm{~m}$ molecule and CD80 enhanced tumorspecific immune responses in mice, the number of cells expressing IFN- $\gamma$, a cytokine secreted by CTL, was evaluated using the IFN- $\gamma$ enzyme-linked immune spot (ELISPOT) assay. Fourteen days after the last immunization, spleenocytes were isolated from the immunized mice, co-cultured in the presence or absence of the P1A nonapeptide (LPYLGWLVF) for $24 \mathrm{~h}$ and the IFN- $\gamma$-producing cell frequency was determined. As shown in Fig. 3, minimal detectable reactivity was observed in splenocytes from P815/neo or P815/P1Aimmunized mice, whereas significant reactivity was observed in $\mathrm{P} 815 / \mathrm{CD} 80$ or $\mathrm{P} 815 / \mathrm{CD} 80-\mathrm{P} 1 \mathrm{~A}$-treated mice $(\mathrm{P}<0.05)$. In particular, no difference in the IFN- $\gamma$-producing cell frequency of lymphocytes was observed in P815-immunized mice after the spleen cells were re-stimulated with the minimal P1A CD8 ${ }^{+} \mathrm{T}$ cell epitope, LPYLGWLVF compared to nonstimulated spleen cells. However, a significant difference was observed in P815/P1A or P815/CD80-P1A-immunized mice $(\mathrm{P}<0.05)$, indicating that the $\mathrm{CD} 8^{+} \mathrm{T}$ cell epitope was correctly processed and that the $\mathrm{P} 1 \mathrm{~A}$-specific $\mathrm{CD} 8^{+} \mathrm{T}$ cell response was effectively induced. Furthermore, these data 
A

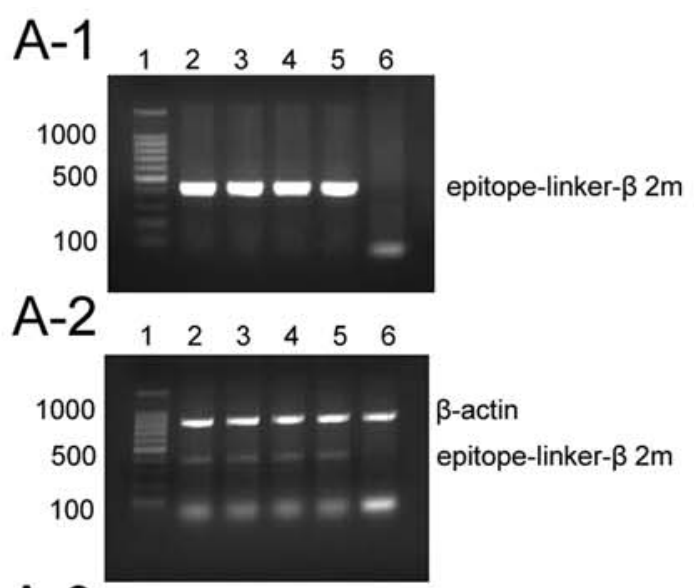

A-3

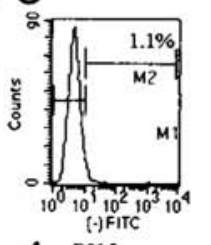

A-4 ${ }^{\text {P815 }}$

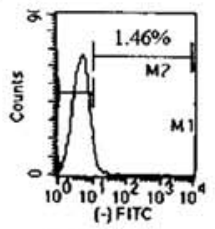

A-5

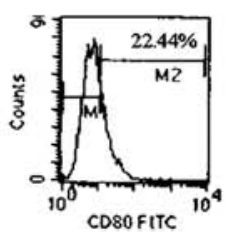

P815/CD80

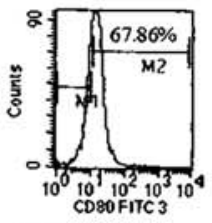

P815/CDS0

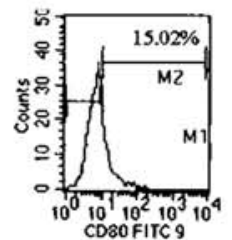

P815/CD80-P198

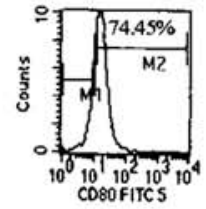

P815/CD80-P1A

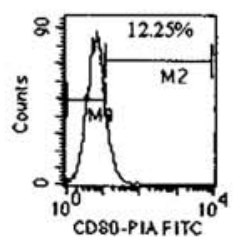

P815/CD80-P1A

B

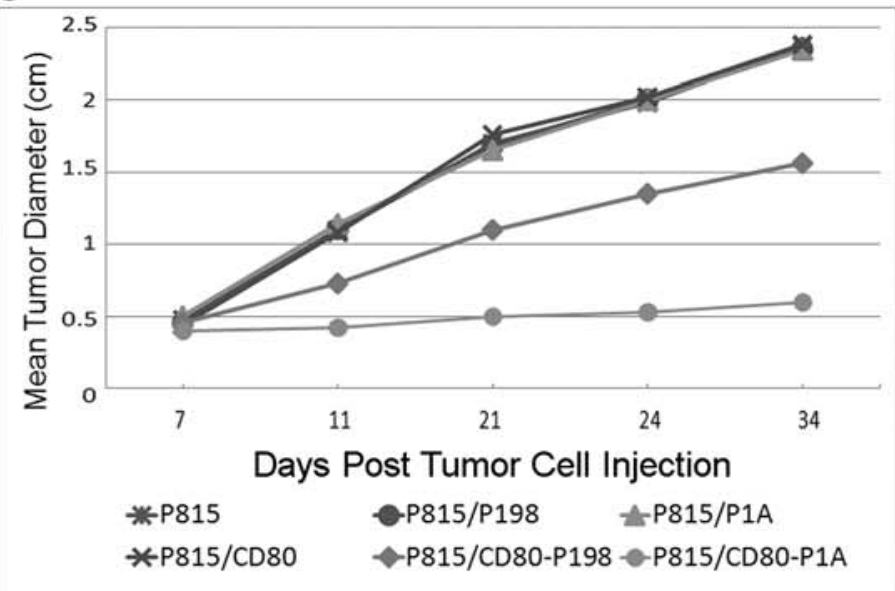

C

A-6

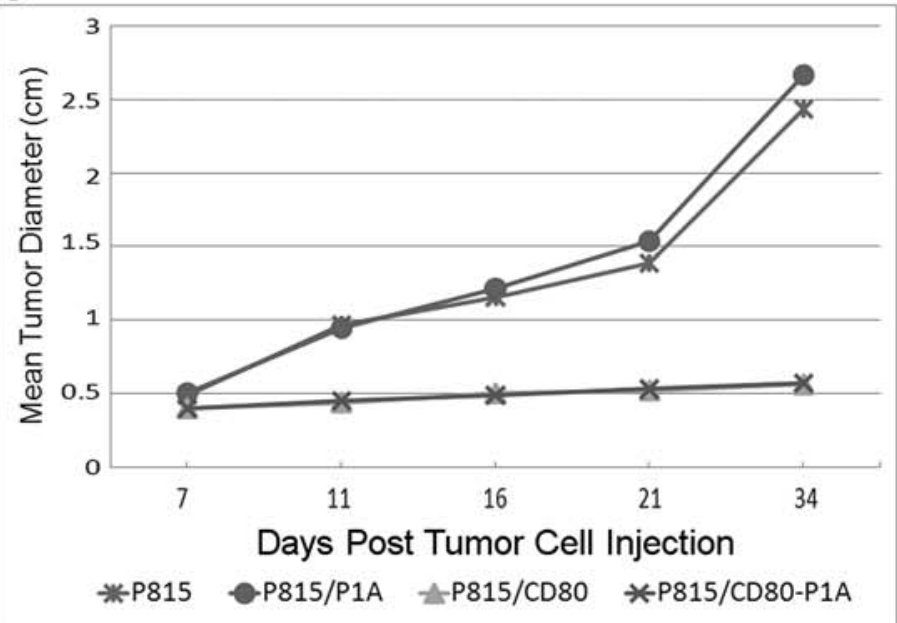

Figure 1. Tumor growth of genemodified P815 cells. Legend on page 5 . 
A

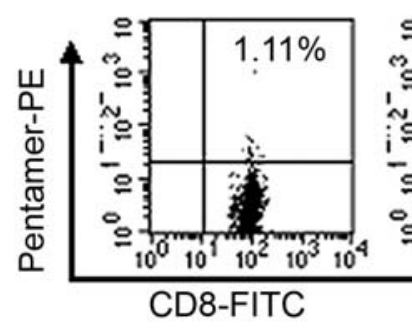

B

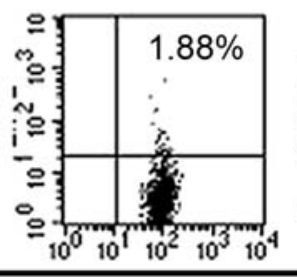

C

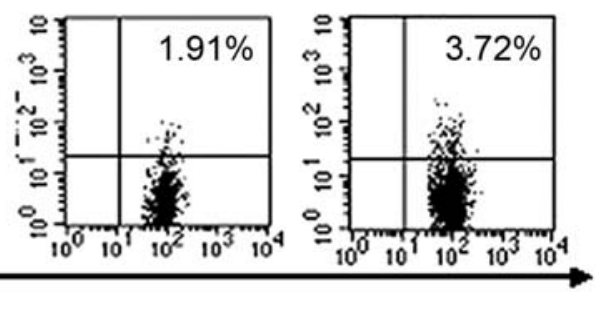

Figure 2. Tumor associated epitope (TAE)-specific $\mathrm{CD}^{+} \mathrm{T}$ cell responses induced by gene-modified P815 cells. Two weeks after the final immunization of mice with irradiated P815 cells (A) P815/neo; (B) P815/P1A; (C) P815/CD80; (D) P815/CD80-P1A), spleen cells were co-stained with a FITC-conjugated anti-CD8 ${ }^{+} \mathrm{mAb}$ and a PE-conjugated $\mathrm{H} 2-\mathrm{L}^{\mathrm{d}}-\mathrm{P} 1 \mathrm{~A}_{35-43}$-pentamer. Samples were analyzed by FACSCalibur. The data presented here are a representative experiment of three independent experiments that gave similar results.

suggest that the expression of CD80 in P815 cells increased the IFN- $\gamma$-producing cell frequency in a non-peptide-specific manner.

Immunization with inactivated P815/CD80-P1A cells induces protection against $P 815$ cells. To determine whether immunization of DBA/2 mice with irradiated gene-modified tumor cells could result in protective immunity, we examined the survival of mice injected with a lethal dose of P815 tumor cells after injection with the irradiated gene-modified P815 cells. Mice (ten animals in each group) were immunized with irradiated P815/CD80-P1A cells, P815/CD80 cells or PBS. Three weeks after immunization, mice were challenged i.p. with wild-type P815 cells and monitored for survival. As shown in Fig. 4, animals immunized with P815/CD80 or PBS showed no evidence of protection from the tumor challenge. However, a strong protective effect was observed in animals immunized with P815/CD80-P1A cells. Sixty days after the tumor challenge, the survival rate of P815/CD80-P1Aimmunized mice was approximately $50 \%$, indicating that the epitope-specific immune response was critical for this protection.

\section{Discussion}

MHC class I molecules bind intracellular peptide antigens, both foreign and self, and display them at the cell surface for scrutiny by $\mathrm{CD} 8+$ CTLs. A single cell may display thousands of different class I bound peptides, the vast majority of which are present in extremely low amounts $(<0.1 \%$ of total) $(21)$. Previous studies have shown that an epitope-linked $32 \mathrm{~m}$ molecule could provide a simple and more efficient means of enhancing the formation of defined $\mathrm{MHC} /$ peptide complexes (9-12). Here, we show that immunization with P815 cells

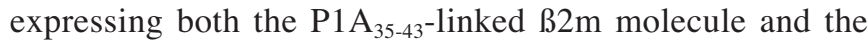
murine $C D 80$ gene elicited an effective antitumor immune response. Furthermore, our data indicate that the immune response to $\mathrm{P} 1 \mathrm{~A}$ was a major component which induces the tumor rejection.

Among the different murine tumors used in antitumor immunity studies, the mastocytoma P815 mouse model is the most thoroughly characterized. Five different antigens are recognized by CTLs on this tumor $(22,23)$. Among these antigens, the major target of the rejection response was shown to consist of a non-americ peptide encoded by the PlA gene, which is silent in normal tissue and expressed in several types of mouse tumor (24). Antigen P198 is a different antigen that is expressed by an immunogenic variant obtained after mutagenesis of P815 tumor cells, and which consists of a peptide corresponding to a point mutation in a gene expressed ubiquitously $(25,26)$. Different modes of immunization with these two antigens have been tested for their efficiency to induce antitumor CTL responses or antitumor protection. In this study, we show that the co-expression of the epitope-

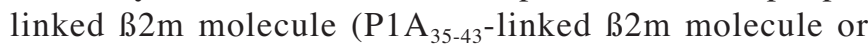
P198 $14-22$-linked $32 \mathrm{~m}$ molecule) and the co-stimulatory molecule CD80 in P815 tumor cells could significantly decrease tumorigenicity in syngeneic $\mathrm{DBA} / 2$ mice. In contrast, the in vivo growth of $\mathrm{P} 815$ cells expressing both the $\mathrm{P}_{1 \mathrm{~A}_{35-43}}$-linked B2m molecule and CD80 is slower than that of P815 cells expressing both the $\mathrm{P}_{198_{14-22}}$-linked B2m molecule and CD80. In agreement with other reports (27), our data show that the

Figure 1. Tumor growth of gene-modified P815 cells. (A) Expression of fusion protein and CD80 in transfected P815 cells. The expression of the peptidelinked $\mathrm{B} 2 \mathrm{~m}$ fusion molecule was confirmed by PCR and RT-PCR. Mouse CD80+ P815 cells were identified by FACS analysis, using an anti-CD80 antibody. (A-1) PCR amplification of epitope-linker- $\$ 2 \mathrm{~m}$ fusion gene from the genomic DNA of trandfected P815 cells; (A-2) RT-PCR analysis of epitope-linker- $32 \mathrm{~m}$ fusion gene in trandfected P815 cells. (1, 100 bp DNA Ladder Marker; 2, RT-PCR result from P815/P1A; 3, RT-PCR result from P815/P1198; 4, RT-PCR result from P815/CD80-P1A; 5, RT-PCR result from P815/CD80-P198; 6, RT-PCR result from P815 cell). (A-3) The expression of CD80 molecule on the surface of G418 selected tranfectants. (A-4) The expression of CD80 molecule on the surface of monoclone cell lines. (B, A-5) Decreased tumor growth of peptide-linked $32 \mathrm{~m}$ molecule and CD80 gene-modified P815 cells. DBA/2 mice (six mice per group) were injected s.c. with 1x10 5 G418-screened tranfectants. Tumors were monitored every 3-5 days once the tumor became palpable. Values are given as mean tumor diameter (cm) \pm SEM, where $n=6$ independent experiments. (C, A-6) Decreased tumor growth of CD80 gene-modified P815 clones. DBA/2 mice (six mice per group) were injected s.c. with $1 \times 10^{5}$ different monoclonal cell lines. Tumors were monitored every 3-5 days once the tumor became palpable. Values are given as mean tumor diameter (cm) \pm SEM, each experiment was repeated with similar results. 

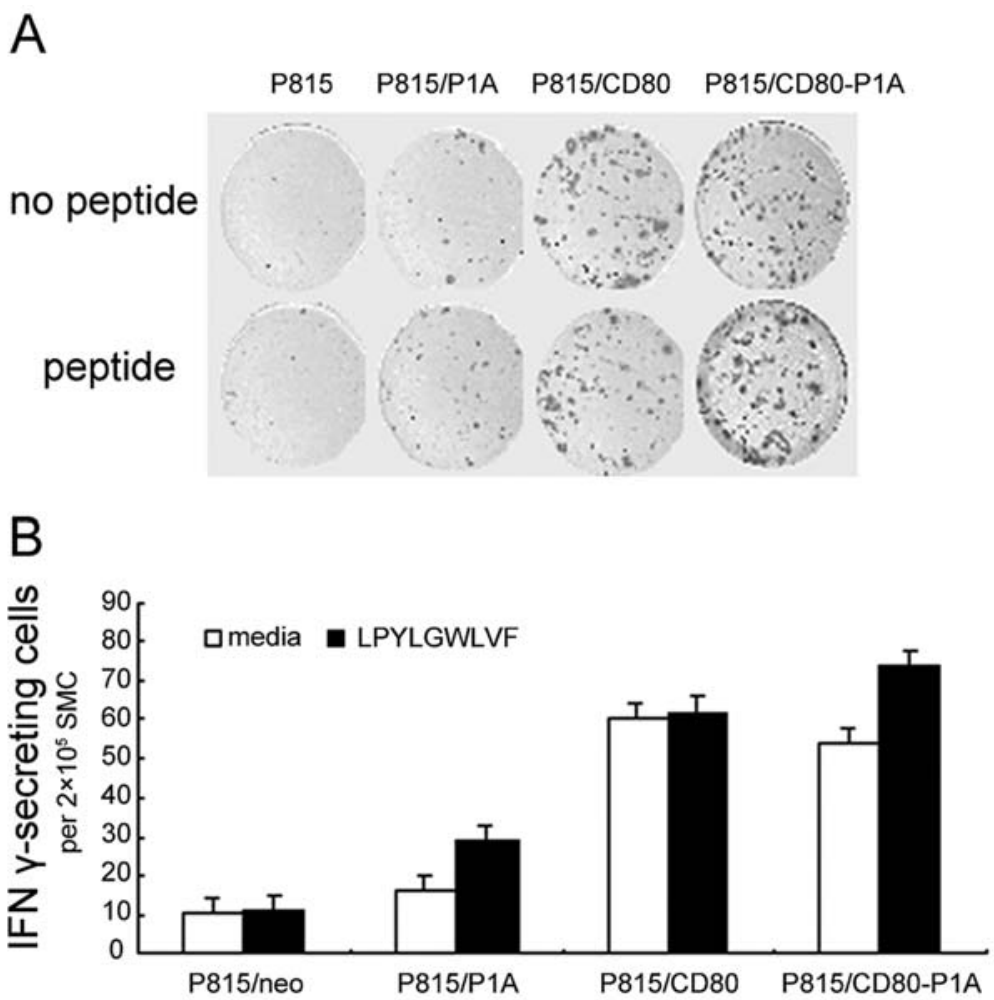

Figure 3. Functional analysis of peptide-specific CD8 ${ }^{+} \mathrm{T}$ cells responses by ELISPOT. P1 $\mathrm{A}_{35-43}$-specific CD8 $\mathrm{T}$ cell responses were measured using the IFN- $\gamma$ ELISPOT as described in Materials and methods. Mice were immunized twice, one week apart and assayed 14 days after the last immunization. Mice were tested for IFN- $\gamma$ responses to LPYLGWLVF peptide (black bars) compared with media alone (white bars) measured by ELISPOT assay ( $\mathrm{n}=3 /$ group). (A) Examples of the spot-forming cell response. (B) The number of spots detected in the IFN- $\gamma$-ELISPOT assays. Each bar represents the mean spot number \pm SEM per $2 \times 10^{5}$ splenocytes. Similar results were seen with repeat experiments.

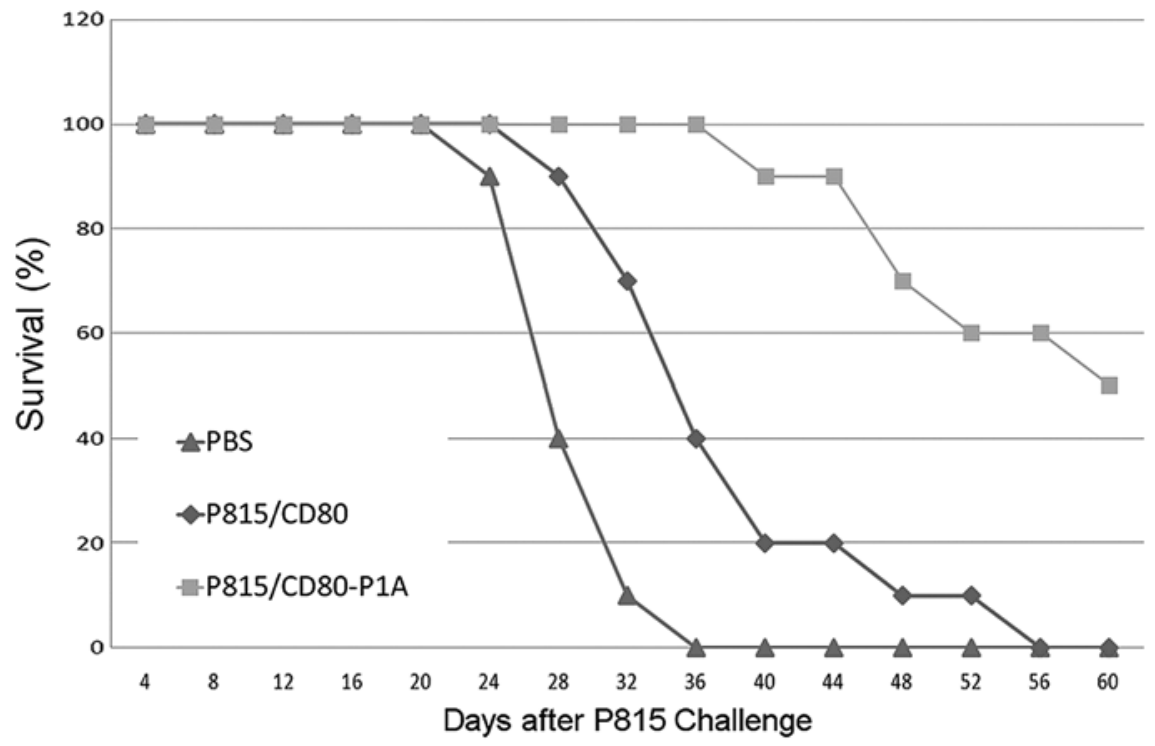

Figure 4. Tumor protection induced by P1A-specific immunity. DBA/2 mice were immunized i.p. with either $10^{6}$ irradiated P815/CD $80-\mathrm{P} 1 \mathrm{~A}$ cells (n=10), $10^{6}$ irradiated P815/CD80 cells $(n=10)$ or PBS $(n=10)$. Three weeks later, $4 \times 10^{5}$ wild-type P815 cells were injected i.p. and survival was monitored daily for 60 days. Each experiment was repeated with similar results.

tumor specific peptide, P1A, is more effective than P198 in terms of inducing antitumor immunity.

Peptide/MHC tetramer analysis and the ELISPOT assay have been widely used to assess antigen-specific $\mathrm{T}$ cell responses $(28,29)$. To investigate the potential mechanism involved in the differences in tumorigenicity of gene-modified P815 cells, we analyzed the P1A-specific CD8 ${ }^{+} \mathrm{T}$ cell responses using the H-2Ld/LPYLGWLVF pentamer analysis and mouse IFN- $\gamma$ ELISPOT assay. We found that although immunization with P815 cells expressing $\mathrm{P}_{1} \mathrm{~A}_{35-43}$-linked $\mathrm{B} 2 \mathrm{~m}$ 
molecule alone increased the frequency of TAE-specific $\mathrm{CD}^{+} \mathrm{T}$ cells, the total number of IFN- $\gamma$-producing splenocytes was still small. These findings may explain why epitopelinked $32 \mathrm{~m}$ molecule expression in P815 cells does not affect its tumorigenecity. Bartholdy et al (30) have reported that vaccinations using DNA vaccines encoding the immunodominant MHC class I-restricted epitopes of lymphocytic choriomeningitis virus covalently linked to $\$ 2 \mathrm{~m}$ only protected against systemic infection, whereas protection against peripheral challenge was limited.

In addition to antigen presentation, successful cancer immunotherapy requires the engagement of the T-cell receptor with an antigen/MHC and a costimulatory molecule such as CD80 or CD86 (31,32). Most tumor cells lack the B7 family $(33,34)$, and thus exhibit T-cell tolerance. Several studies (35-37) have shown that tumor cell vaccines expressing the co-stimulatory molecule, CD80, can induce much stronger antitumor immunity than the wild-type tumor vaccine. Therefore, in this study, the co-expression vector of epitopelinked $32 \mathrm{~m}$ molecule and CD80 was constructed and transfected into P815 cells. We show that the expression of the co-stimulatory molecule CD80 in P815 cells significantly increases the number of IFN- $\gamma$-producing splenocytes, which is non-specific to the non-apeptide LPYLGWLVF. This may explain the difference in tumorigenicity between CD80modified tumor cells and other tumor cells.

In order to evaluate the protective capacity of different modified P815 tumor vaccines, we have further examined the ability of the peptide-linked $\beta 2 \mathrm{~m}$ molecule to induce protective immunity against wild-type P815 challenge. Compared with P815 cells expressing the co-stimulatory molecule CD80 alone, immunization with irradiated P815 cells expressing both the epitope-linked B2m molecule and CD80 significantly elicited protective immunity. We found that approximately $50 \%$ of the mice immunized with P815 cells expressing both the epitope-linked $32 \mathrm{~m}$ molecule and CD80 were protected against a challenge with a lethal dose of P815 tumor cells injected into the peritoneal cavity, consistent with previous studies $(19,20)$. Therefore, our results indicate that the coexpression of both the peptide-linked $\beta 2 \mathrm{~m}$ molecule and costimulatory molecule CD80 in P815 cells elicits antigenspecific $\mathrm{T}$ cell responses. Our data suggest that the immune response to $\mathrm{P} 1 \mathrm{~A}$ was the major component of the tumor rejection.

In summary, our findings show that tumor vaccines modified with peptide-linked $32 \mathrm{~m}$ molecule and CD80 can generate a more effective antitumor immunity than a singlemodified tumor vaccine in vivo, indicating that the peptidelinked $32 \mathrm{~m}$ molecule and CD80 were able to stimulate antitumor immune responses synergistically. These results provide experimental evidence that supports the feasibility and effectiveness of this novel approach in cancer immunotherapy.

\section{Acknowledgements}

This work was supported by The National Key Program for Basic Research of China (2004CB518804), The Science and Technology Commission of Shanghai (S30205, 06SR07110, 07JC14034 and 08ZR1412500).

\section{References}

1. Cresswell P: Intracellular surveillance: controlling the assembly of mhc class I-peptide complexes. Traffic 1: 301-305, 2000.

2. Williams A, Peh CA and Elliott T: The cell biology of mhc class I antigen presentation. Tissue Antigens 59: 3-17, 2002.

3. Levitsky V, Zhang QJ, Levitskaya J and Masucci MG: The life span of major histocompatibility complex-peptide complexes influences the efficiency of presentation and immunogenicity of two class I-restricted cytotoxic T lymphocyte epitopes in the Epstein-Barr virus nuclear antigen 4. J Exp Med 183: 915-926, 1996.

4. Gervois N, Guilloux Y, Diez E and Jotereau F: Suboptimal activation of melanoma infiltrating lymphocytes (TIL) due to low avidity of TCR/MHC-tumor peptide interactions. J Exp Med 183: 2403-2407, 1996.

5. Tsomides TJ, Aldovini A, Johnson RP, Walker BD, Young RA and Eisen HN: Naturally processed viral peptides recognized by cytotoxic T lymphocytes on cells chronically infected by human immunodeficiency virus type 1. J Exp Med 180: 1283-1293, 1994.

6. Chung DH, Dorfman J, Plaksin D, et al: Nk and ctl recognition of a single chain $\mathrm{H}-2 \mathrm{dd}$ molecule: distinct sites of $\mathrm{H}-2 \mathrm{dd}$ interact with NK and TCR. J Immunol 163: 3699-3708, 1999.

7. Lybarger L, Yu YY, Miley MJ, et al: Enhanced immune presentation of a single-chain major histocompatibility complex class I molecule engineered to optimize linkage of a c-terminally extended peptide. J Biol Chem 278: 27105-27111, 2003.

8. Williams MA and Bevan MJ: Cutting edge: a single MHC class IA is sufficient for CD8 memory T cell differentiation. J Immunol 175: 2066-2069, 2005.

9. Uger RA and Barber BH: Creating ctl targets with epitope-linked beta 2-microglobulin constructs. J Immunol 160: 1598-1605, 1998.

10. Margalit A, Sheikhet HM, Carmi Y, et al: Induction of antitumor immunity by CTL epitopes genetically linked to membrane-anchored beta2-microglobulin. J Immunol 176: 217-224, 2006

11. Huang B, Mao CP, Peng S, He L, Hung CF and Wu TC: Intradermal administration of DNA vaccines combining a strategy to bypass antigen processing with a strategy to prolong dendritic cell survival enhances DNA vaccine potency. Vaccine 25: 7824-7831, 2007.

12. Fang L, Wang K, Liu X, et al: A study on anti-tumor immunity induced by gene-modified melanoma B16 cells. Oncol Rep 19: 1589-1595, 2008.

13. Liu Y and Linsley PS: Costimulation of T-cell growth. Curr Opin Immunol 4: 265-270, 1992.

14. Mueller DL, Jenkins MK and Schwartz RH: Clonal expansion versus functional clonal inactivation: a costimulatory signalling pathway determines the outcome of $\mathrm{T}$ cell antigen receptor occupancy. Annu Rev Immunol 7: 445-480, 1989.

15. Wang B, Maile R, Greenwood R, Collins EJ and Frelinger JA: Naive CD8 ${ }^{+} \mathrm{T}$ cells do not require costimulation for proliferation and differentiation into cytotoxic effector cells. J Immunol 164: 1216-1222, 2000.

16. Cavallo F, Martin-Fontecha A, Bellone M, et al: Co-expression of B7-1 and ICAM-1 on tumors is required for rejection and the establishment of a memory response. Eur J Immunol 25: 1154-1162, 1995

17. La Motte RN, Sharpe AH, Bluestone JA and Mokyr MB: Host B7-1 and B7-2 costimulatory molecules contribute to the eradication of B7-1-transfected P815 tumor cells via a CD8 ${ }^{+} \mathrm{T}$ cell-dependent mechanism. J Immunol 162: 4817-4823, 1999.

18. Liu X, Zhang L, Zhang X, et al: The effect of co-expression costimulatory molecule CD80 on uptake of antigen peptideMHC class I-GFP complex by specific T cells. Int J Oncol 30: 1389-1396, 2007.

19. Zhang H, Wang H, Zhang J, et al: Enhanced therapeutic efficacy by simultaneously targeting two genetic defects in tumors. Mol Ther 17: 57-64, 2009.

20. Brandle D, Bilsborough J, Rulicke T, Uyttenhove C, Boon T and van den Eynde BJ: The shared tumor-specific antigen encoded by mouse gene P1A is a target not only for cytolytic T lymphocytes but also for tumor rejection. Eur J Immunol 28: 4010-4019, 1998.

21. Engelhard VH: Structure of peptides associated with class I and class II MHC molecules. Annu Rev Immunol 12: 181-207, 1994. 
22. Brichard VG, Warnier G, van Pel A, Morlighem G, Lucas S and Boon T: Individual differences in the orientation of the cytolytic $\mathrm{T}$ cell response against mouse tumor P815. Eur J Immunol 25 : 664-671, 1995.

23. Uyttenhove C, Maryanski J and Boon T: Escape of mouse mastocytoma P815 after nearly complete rejection is due to antigen-loss variants rather than immunosuppression. J Exp Med 157: 1040-1052, 1983.

24. Van den Eynde B, Lethe B, van Pel A, De Plaen E and Boon T: The gene coding for a major tumor rejection antigen of tumor $\mathrm{P} 815$ is identical to the normal gene of syngeneic DBA/2 mice. J Exp Med 173: 1373-1384, 1991.

25. Sibille C, Chomez P, Wildmann C, et al: Structure of the gene of TUM-transplantation antigen P198: a point mutation generates a new antigenic peptide. J Exp Med 172: 35-45, 1990.

26. Uyttenhove C, van Snick J and Boon T: Immunogenic variants obtained by mutagenesis of mouse mastocytoma P815. I. Rejection by syngeneic mice. J Exp Med 152: 1175-1183, 1980.

27. Mazouz N, Ooms A, Moulin V, van Meirvenne S, Uyttenhove C and Degiovanni G: CD40 triggering increases the efficiency of dendritic cells for antitumoral immunization. Cancer Immun 2: 2, 2002.

28. Brinkman M, Walter J, Grein S, et al: Beneficial therapeutic effects with different particulate structures of murine polyomavirus VP1-coat protein carrying self or non-self CD8 T cell epitopes against murine melanoma. Cancer Immunol Immunother 54: 611-622, 2005.

29. Takada I, Noguchi Y, Kenjo A, et al: Analysis of CD8 T-cell response by IFNgamma elispot and H-21(d)/PR11A tetramer assays in PRL1A multiple antigen peptide-immunized and RL male 1-bearing balb/c and (balb/c x c57bl/6) f(1) mice. Cancer Sci 95: 254-259, 2004
30. Bartholdy C, Stryhn A, Hansen NJ, Buus S and Thomsen AR: Incomplete effector/memory differentiation of antigen-primed $\mathrm{CD} 8^{+} \mathrm{T}$ cells in gene gun DNA-vaccinated mice. Eur J Immunol 33: 1941-1948, 2003.

31. Fagnoni FF, Takamizawa M, Godfrey WR, et al: Role of b70/ $\mathrm{B} 7-2$ in $\mathrm{CD}^{+} \mathrm{T}$-cell immune responses induced by dendritic cells. Immunology 85: 467-474, 1995.

32. Judge TA, Tang A and Turka LA: Immunosuppression through blockade of CD28:B7-mediated costimulatory signals. Immunol Res 15: 38-49, 1996.

33. Hui K, Grosveld F and Festenstein H: Rejection of transplantable AKR leukaemia cells following MHC DNA-mediated cell transformation. Nature 311: 750-752, 1984.

34. Wallich R, Bulbuc N, Hammerling GJ, Katzav S, Segal S and Feldman M: Abrogation of metastatic properties of tumour cells by de novo expression of $\mathrm{H}-2 \mathrm{~K}$ antigens following $\mathrm{H}-2$ gene transfection. Nature 315: 301-305, 1985.

35. Choi KJ, Kim JH, Lee YS, et al: Concurrent delivery of GMCSF and B7-1 using an oncolytic adenovirus elicits potent antitumor effect. Gene Ther 13: 1010-1020, 2006.

36. Si SY, Hu PZ, Huang YY, et al: Tumor cells with B7.1 and transmembrane anchored staphylococcal enterotoxin a generate effective antitumor immunity. Biochem Biophys Res Commun 347: 208-214, 2006.

37. Townsend SE and Allison JP: Tumor rejection after direct costimulation of $\mathrm{CD}^{+} \mathrm{T}$ cells by B7-transfected melanoma cells. Science 259: 368-370, 1993. 